\title{
Téoros
}

Revue de recherche en tourisme

\section{Tourisme gai et Internet}

La création de Direction Gay Québec

\section{Sylvie Bertrand}

Volume 19, numéro 2, été 2000

Le tourisme des gais et des lesbiennes

URI : https://id.erudit.org/iderudit/1071968ar

DOI : https://doi.org/10.7202/1071968ar

Aller au sommaire du numéro

Éditeur(s)

Université du Québec à Montréal

ISSN

0712-8657 (imprimé)

1923-2705 (numérique)

Découvrir la revue

Citer cet article

Bertrand, S. (2000). Tourisme gai et Internet : la création de Direction Gay

Québec. Téoros, 19(2), 60-60. https://doi.org/10.7202/1071968ar d'utilisation que vous pouvez consulter en ligne.

https://apropos.erudit.org/fr/usagers/politique-dutilisation/ 


\section{TOURISME GaI ET INTERNET}

\section{LA CRÉATION DE DIRECTION GAY QUÉBEC}

\section{Sylvie Bertrand}

Les gais et les lesbiennes sont friands des nouvelles technologies de communications. Internet est donc l'outil par excellence pour la constitution du Village gai planétaire. Des groupes communautaires et des individus de pays éloignés peuvent coordonner leurs actions, échanger leur expérience et favoriser des rencontres. Les touristes peuvent préparer leurs vacances et profiter de l'accueil de la communauté locale. Enfin, par le truchement des universités et des cafés Internet, le médium se démocratise.

Bien qu'il existe une panoplie d'organismes et de commerces gais et lesbiens ayant pignon sur le Net, seul directiongayquebec. com se définit comme portail interactif pour la promotion du Québec comme destination touristique gaie. Direction Gay Québec offre à la communauté et à l'industrie touristique un service qui comporte trois volets : un magazine d'actualité avec des chroniques diverses d'intérêt gai et lesbien, une section de services communautaires avec groupes de discussion et, enfin, un important volet touristique. Le site contiendra une mine de renseignements mis à jour quotidiennement avec la collaboration de nombreux chroniqueurs et correspondants québécois et étrangers. Il sera lancé officiellement en septembre 2000 , mais les internautes y ont accès depuis juillet. Le financement de cette entreprise sera assuré par la présence de bannières publicitaires sur le site, les cotisations des membres, une boutique en ligne et les commissions sur les réservations.

Le volet touristique du site offre un service de réservations en ligne (transports et hébergement), un service personnalisé de planification d'itinéraires, des listes à jour d'établissements gay friendly dans tout le Québec et un calendrier des événements d'envergure. Le site servira aussi de portail vers le monde par la mise en réseau des destinations gaies internationales.
Selon certaines études de marché de la clientèle touristique gaie et lesbienne, les voyageurs américains, dans un pourcentage très supérieur aux années précédentes, annoncent leur intention de voyager au $\mathrm{Ca}$ nada et, en particulier, à Montréal. L'ensemble du Québec offre un potentiel encore sous-exploité et Direction Gay Québec prône l'utilisation de médias novateurs pour en faire la promotion. Internet favorise la mise à jour en temps réel de l'information et la mise en réseau de tous les partenaires touristiques à l'échelle de la province. Les études affirment aussi que les consommateurs gais et lesbiens privilégient une information provenant de la communauté et qu'ils sont très fidèles aux entreprises qui leur réservent un accueil empreint de respect et de considération.

Ayant comme mission de faire la promotion de la spécificité québécoise en vue de la faire découvrir à un plus grand nombre de gais et de lesbiennes d'ici et d'ailleurs, le site est unique par sa convivialité, son contenu élaboré et les nombreuses possibilités de recherche de renseignements spécifiques. En plus de son concept interactif, le site est structuré en versions anglaise et française et une version espagnole est prévue à moyen terme. Facteur encore plus important, le site attribue une place égale aux gais et aux lesbiennes et l'interface d'accueil offre à l'usager l'un ou l'autre de ces profils pour naviguer sur le site. Direction Gay Québec entend ainsi favoriser l'expression de la diversité de la communauté et donner aux lesbiennes une visibilité dont elles sont loin de profiter dans notre société actuelle.

\section{UN DÉFI DE TAILLE}

Les problèmes sont nombreux, qu'il s'agisse d'obtenir la collaboration des milieux politique, communautaire et du monde des affaires, des sources fiables d'information et des chroniqueurs chevronnés. La difficulté est moindre pour les villes de Montréal et de Québec qui sont déjà établies comme destinations gaies, mais il en va autrement des autres régions du Québec où il faut sensibiliser les propriétaires d'entreprises au potentiel de ce marché. Le défi consiste en fait à implanter un réseau de partenaires à l'échelle du Québec, puis des correspondants à travers le monde. Nombreux sont les homosexuels établis en dehors des circuits gais qui aspirent à un meilleur accueil hors ghetto. Les lesbiennes, quant à elles, bien qu'elles brillent par leur discrétion, sont toujours nombreuses à parcourir nos régions, mais elles demeurent ouvertes au tourisme urbain. Le site vise aussi à diversifier l'offre touristique pour gais et lesbiennes et à améliorer l'accueil qui leur est réservé dans tous les milieux et dans toutes les régions du Québec.

Sylvie Bertrand, rédactrice en chef de Direction Gay Québec, a été, entre autres, éditrice et rédactrice en chef d'un mensuel, traductrice et représentante publicitaire pour le Canadien Pacifique. 